\title{
Hepatitis C infection in an Irish antenatal population
}

\author{
CM Healy ${ }^{1,4}$, MT Cafferkey ${ }^{1,4}$, A Conroy ${ }^{6}$, S Dooley, WW Hall ${ }^{6}$, M Beckett', R. Mackey', TA Clarke ${ }^{1,4}$, MJ White ${ }^{2,5}$, \\ WA Gorman ${ }^{3,5}, \mathrm{KM}^{\mathrm{B}}$ Butler ${ }^{14,5}$ \\ Rotunda Hospital', Dublin, Coombe Women's Hospital ${ }^{2}$, Dublin, National Maternity Hospital ${ }^{3}$, Holles St., Dublin, \\ The Children's Hospital', Temple St, Dublin, Our Lady's Hospital for Sick Children ${ }^{5}$, Crumlin, Dublin, \\ Virus Reference Laboratory ${ }^{6}$, University College, Dublin, Ireland
}

\section{Abstract}

Background Hepatitis C infection (HCV) has an estimated seroprevalence of 1-2\% in women of child-bearing age and vertical transmission rate of $5-15 \%$.

Aims To characterise the current trends of HCV in an Irish antenatal population.

Methods Infants of HCV seropositive women, born 1994 to 1999, were referred to the Paediatric Infectious Diseases service. Maternal details were collected retrospectively.

Results 296 HCV seropositive women were studied. 244 (82\%) were infected through intravenous drug use (IVDU), 25 $(8 \%)$ through heterosexual contact and $13(7 \%)$ via blood products. Nine women had no identifiable risk factors. Coinfection with other blood borne viruses was uncommon (4.7\% HIV, 3.4\% hepatitis B). Of 84 women tested for HCVRNA, $46(55 \%)$ were positive. Eighty three (26\%) delivered prematurely; the caesarean section rate was $11 \%$.

Conclusions $\mathrm{HCV}$ is increasingly detected in antenatal clinics. Heterosexual contact is a mode of spread. Maternal $\mathrm{HCV}$ viraemia can be variable in pregnancy. Further study of $\mathrm{HCV}$ in pregnancy is needed to define the impact of pregnancy on $\mathrm{HCV}$, accurately predict infant outcome and selectively target interventions to women at greatest risk of transmission.

\section{Introduction}

Hepatitis $\mathrm{C}$ infection (HCV) is the major cause of non-A, non$\mathrm{B}$ hepatitis, described as the "hidden epidemic" with an estimated 170 million individuals infected world-wide. Although $\mathrm{HCV}$ was first described in blood transfusion recipients, other routes of transmission are now recognised. The importance of sexual or household contact as modes of transmission is controversial $^{1-4}$ and remains to be defined. Vertical transmission from mother to infant, originally thought to be extremely rare, occurs in five to fifteen per cent of deliveries to HCV infected women and will potentially impact significantly on paediatric service requirements. To better anticipate paediatric needs, we sought to characterise the current trends in HCV infection in an Irish antenatal population.

\section{Methods}

Since 1994, a prospective observational study of infants born to $\mathrm{HCV}$ infected mothers and referred to the Paediatric Infectious Diseases service at The Children's Hospital, Temple St. and Our Lady's Hospital for Sick Children, Crumlin is being carried out ${ }^{5,6}$ and will be reported shortly. Infant referrals are predominantly from three Dublin maternity hospitals. Women attending antenatal clinics are offered testing for $\mathrm{HCV}$ if they report risk factors for $\mathrm{HCV}$ acquisition (illicit drug use, transfusion of blood/blood products, sexual contact with a HCV infected partner, tattoos/body piercing, history of jaundice), develop jaundice or abnormal liver function tests in pregnancy, or if they request screening. In the course of the infant study, retrospective data on maternal demographics, risk factors for infection and laboratory results (where available) were gathered and are presented here.

All serological and molecular testing for $\mathrm{HCV}$ is performed at the Virus Reference Laboratory, University College, Dublin. Hepatitis C antibody is detected using one or more commercial third generation enzyme immunoassays (Ortho, Abbott Axysm). Confirmation of antibody status is determined using the RIBA-3 assay. Hepatitis C RNA is detected using the Amplicor HCV assay (Roche) and an in-house RT-PCR assay (detects $>100$ copies $/ \mathrm{ml}$ ). Viral load is measured by branched DNA signal amplification (Chiron) and HCV genotype is identified by restriction fragment length polymorphism (RFLP). ${ }^{7}$

\section{Results}

Two hundred and ninety six women, 18 of whom had more than one pregnancy, attending for antenatal care tested positive for HCV during the years 1994-1999 and presented with their infants to the Paediatric Infectious Diseases service. These mother-infant pairs accounted for approximately $65 \%$ 
(628 of 966) of all positive tests for hepatitis C originating from the maternity hospitals during this period. However, as individuals were selected for testing, and as the total number of tests received (even if each test represented a unique obstetric patient) represented less than $5 \%$ of the obstetric population, no estimate of seroprevalence can be made. There was a marked escalation in the numbers attending the service over the years; an eight fold increase from 14 in 1994 to 111 in 1999 (Figure 1). Fifty eight per cent (184) of women attended the Rotunda, 33\% (104) the Coombe Women's Hospital and $8 \%(25)$ the National Maternity Hospital, Holles Street. Maternal demographics and risk factors for infection are shown in Table 1.

Prior to 1998 the decision to test women for HIV or hepatitis B surface antigen was dependent on the treating clinician. Universal screening for HIV and hepatitis B surface antigen has been offered in the Rotunda since January 1998. Universal HIV screening is performed in the other hospitals since 1999. Of 277 HCV seropositive mothers who agreed to HIV testing in pregnancy or at delivery, $13(4.7 \%)$ were positive. Two additional women tested HIV positive within one year after infant delivery. Nine of 262 (3.4\%) tested for hepatitis B had detectable surface antigen.

The degree of evaluation of maternal hepatitis $\mathrm{C}$ infection in pregnancy was variable. Hepatitis $\mathrm{C}$ genotype was defined in 51 women during the antenatal period (33 type 1, 15 type 3, 1 type 4). Assessment of maternal viraemia by polymerase chain reaction (PCR), antenatally or peri-partum, was performed in 84 women. HCV-RNA was detected in 46 (55\%). Detection of HCV-RNA could be intermittent in pregnancy as noted in two of four women who were tested on more than one occasion.

Eighty three women $(26 \%)$ delivered at less than 38 weeks gestation (range 27-37); thirty four had caesarean sections (28 elective, 6 elective) giving a caesarean section rate of $11 \%$ in this cohort. This compared with hospital caesarean section rates of $9-19 \%$ over the same time period.

\section{Discussion}

The true seroprevalence of hepatitis $\mathrm{C}$ in women of childbearing age is not known. Large-scale seroprevalence studies have not been done, however, the Centre for Disease Control in Atlanta estimate that approximately 1-2\% of women of child-bearing age in the US are HCV infect-

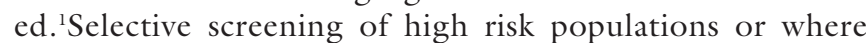
clinically indicated has been the policy in Irish antenatal clinics. This does not permit accurate determination of seroprevalence; nevertheless the increase in the numbers of HCV antibody positive women detected over this study period is striking. Some of this represents improved awareness and case ascertainment as the numbers of samples received for testing in the Virus Reference Laboratory have also increased. Most HCV infected women are Irish, with few cases as yet identified in women from endemic areas.

IVDU is currently the primary risk factor for HCV acquisition in an antenatal population. However, the number of mothers who consistently denied IVDU, and whose only identified risk factor is sexual contact with a known $\mathrm{HCV}$ infected partner, is high $(9 \%)$. While some of this may reflect undisclosed IVDU, we believe that the risk categories as given are reliable. The role of sexual transmission in the spread of HCV is often discounted. ${ }^{1-4}$ This study supports the view that the importance of sexual spread should no longer be overlooked, highlighting the need for education of the general population and the incorporation of such information into HCV prevention strategies. Similarly, the detection of $\mathrm{HCV}$ in women who do not belong to any
Figure 1: Numbers of HCV infected women detected 19941999

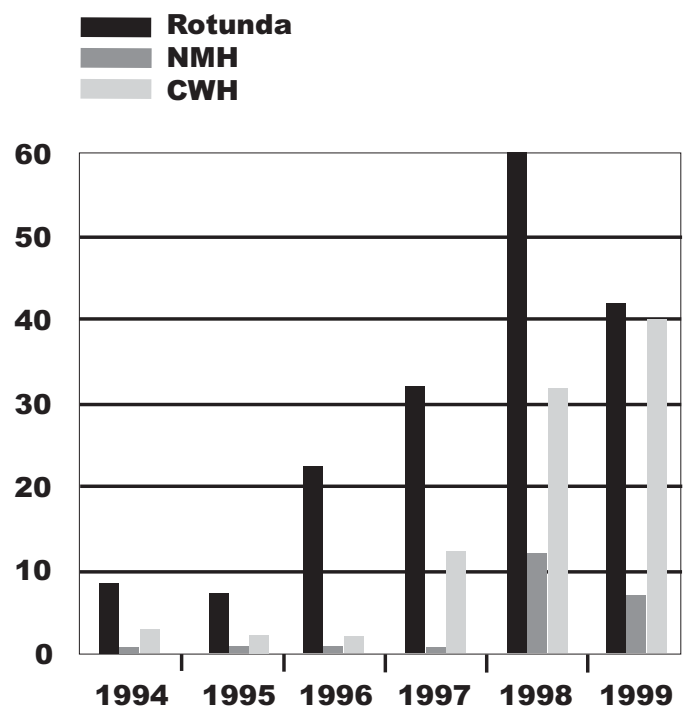

Table 1: Maternal demographics and risk factors for infection

$\begin{array}{lrr}\text { Age at delivery (years) } & & \\ \text { Median (range) } & 24 & (16-41) \\ \text { Nationality No (\%) } & & \\ & & \\ \text { Ireland } & 289 & (97) \\ \text { Africa } & 6 & (2) \\ \text { Eastern Europe } & 1 & (<1) \\ & & \\ \text { Risk factors for infection No (\%) } & \\ \text { IVDU } & 244 & (83) \\ \text { Heterosexual exposure } & 25 & (8) \\ \text { Infected blood products } & 13 & (7) \\ \text { Tattoos } & 2 & (<1) \\ \text { No risk identified } & 9 & (3) \\ \end{array}$

of the recognised "high risk" groups is worrying, suggesting either greater transmissibility through sexual contact or of the existence of other unrecognised modes of transmission. This may herald even more widespread prevalence than previously thought.

Twenty six percent of women delivered at less than 38 weeks gestation. However, the caesarean section rate is surprisingly low at 11 per cent perhaps reflecting the young age of the cohort.

The numbers of women infected with other blood borne viruses is low given the predominance of IVDU in this cohort but consistent with previous reports of the prevalence of these pathogens amongst IVDU attending Dublin treatment centres. $^{13,14}$ It is not possible in this study to reliably assess the effects of pregnancy on HCV disease activity. Few women had evaluations of liver function or repeated measures of viral activity during pregnancy. More than $50 \%$ of those in whom HCV PCR testing was carried out had HCV-RNA detected. As noted, this can be intermittent and a single negative PCR test in pregnancy does not accurately reflect viral activity throughout gestation. Further studies are needed to address 
this question.

HCV is transmitted vertically in $5-15 \%$ of all pregnancies in HCV positive women. ${ }^{5,6,8-11}$ More frequent determinations of $\mathrm{HCV}$ viraemia in pregnancy might permit more accurate prediction of infant outcome. It is likely that for women who remain consistently PCR negative during pregnancy the risk of vertical transmission might approach zero. ${ }^{12}$ Knowledge of maternal viraemia would also permit more selective targeting of interventions to reduce transmission at women at greatest risk, as these become available. This may become critical if early indicators that caesarean section can significantly reduce the risk of vertical transmission of $\mathrm{HCV}$ are confirmed. ${ }^{6}$

Many women in this cohort - while accessing care for their infants - did not attend adult hepatology services and were often poorly informed regarding their own health status. They were often unaware of recommendations such as vaccination against hepatotropic viruses (A and $\mathrm{B}$ ), or restriction of alcohol intake in this condition. Attendance for antenatal and paediatric care offers an opportunity to educate women and link them in with appropriate services. Regular assessment of liver function is advisable in HCV infection and this assumes even greater importance as new and effective therapies become available.

\section{Conclusion}

Hepatitis C is an increasingly detected problem in women attending antenatal clinics, in part reflecting improved ascertainment and perhaps reflecting increasing seroprevalence in the community. This has implications for future resource requirements of both adult and paediatric services. While IVDU remains the most significant risk factor for maternal infection, heterosexual contact with an infected partner must not be discounted as a potential mode of spread. The detection of $\mathrm{HCV}$ in women who do not belong to traditional high risk categories may point to the need for wider screening, particularly if obstetric interventions such as caesarean section are proved to interrupt vertical transmission. ${ }^{6}$ Maternal $\mathrm{HCV}$ viraemia can be variable in pregnancy. More systematic study of HCV infection in pregnancy is needed to accurately determine seroprevalence, to define the impact of pregnancy on $\mathrm{HCV}$, and to permit more accurate prediction of infant outcome thus facilitating selective targeting of interventions to women at greatest risk of transmission.

\section{Acknowledgments}

The authors would like to acknowledge the assistance of medical and nursing staff caring for women in this observational study.

\section{References}

1. American Academy of Pediatrics. Hepatitis C. In: Peter G, ed.1997 Red Book: Report of the Committee on Infectious Diseases. 24th ed. Elk Grove Village, IL: American Academy of Pediatrics; 1997: (260-4)
2. Thomas DL, Zenilman JM, Alter HJ et al., Sexual transmission of hepatitis $\mathrm{C}$ virus among patients attending sexually transmitted diseases clinics in Baltimore - an analysis of 309 sex partnerships. J. Infect. Dis. 1995 Apr; 171(4): 76875

3. Alter MJ, Coleman PJ, Alexander WJ et al., Importance of heterosexual activity in the transmission of hepatitis $\mathrm{B}$ and non-A, non-B hepatitis. JAMA 1989 Sep 1; 262 (9): 201-5 4. Osmond DH, Padian NS, Sheppard HW et al., Risk factors for hepatitis $\mathrm{C}$ seropositivity in heterosexual couples. JAMA 1993; 269: 361-5

5. Healy M, Cafferkey M, Beckett M et al. Characteristics of infants of hepatitis $\mathrm{C}$ infected mothers in the Republic of Ireland. 3rd Spring Meeting, Royal College of Paediatrics and Child Health, University of York 12-15 April 1999; Abstract P25

6. Gibb DM, Goodall RL, Butler K et al. Mother to child transmission of hepatitis $\mathrm{C}$ virus: evidence for preventable peripartum transmission. Lancet 2000; 356: 904-7

7. Davidson F. et al. Survey of major genotypes and subtypes of hepatitis $\mathrm{C}$ virus using RFLP of sequences amplified from the 5' non-coding region. Journal of General Virology (1995) 76, 1197-1204.

8. Resti M; Azzari C; Mannelli F et al. Mother to child transmission of hepatitis $\mathrm{C}$ virus: prospective study of risk factors and timing of infection in children born to women seronegative for HIV-1. Tuscany Study Group on Hepatitis C Virus Infection. BMJ. 317(7156): 437-41, 1998 Aug.15.

9. American Academy of Pediatrics Committee on Infectious Diseases.

Hepatitis C virus infection. Pediatrics 1998; 101: 481-85

10. Tovo PA, Palomba E, Ferraris G et al. Increased risk of maternal-infant hepatitis $\mathrm{C}$ virus transmission for women coinfected with human immunodeficiency virus type 1 . Italian study Group for HCV Infection in Children. Clin Infect Dis 1997; 25: 1121-4

11. Thomas SL, Newell ML, Peckham CS, Ades AE, Hall $\mathrm{AJ}$. A review of hepatitis $\mathrm{C}$ virus $(\mathrm{HCV})$ vertical transmission: risks of transmission to infants born with and without $\mathrm{HCV}$ viraemia or human immunodeficiency virus infection. Int $J$ Epidemiol 1998; 27: 108-17.

12. Dore GJ, Kaldor JM, McGaughan WM. Systematic review of role of polymerase chain reaction in defining infectiousness among people infected with hepatitis $\mathrm{C}$ virus. $B M J$ 1997; 315: 333-37.

13. Smyth BP, Keenan E, O'Connor JJ. Bloodborne viral infection in Irish injecting drug users. Addiction 1998; 93: 1649-56

14. Dorman A, Keenan E, Schuttler C, Merry J, O’Connor JJ. HIV risk behaviour in Irish intravenous drug users. Ir J Med Sci Oct-Dec 1997, 166(4) 235-8

Correspondence to: $\mathrm{Dr} K$ Butler, Consultant in Paediatric Infectious Diseases, Our Lady's Hospital for Sick Children, Crumlin, Dublin 12. 